\title{
TRAJECTORY ATTRACTORS OF ENERGY BALANCE CLIMATE MODELS WITH BIO-FEEDBACK
}

\author{
GEORG HetZER
}

Abstract. Motivated by coupling an energy balance climate model and a two-species competition model for the bio-sphere, one is led to the study of functional reaction-diffusion equations with memory and a nonlocal Volterra operator. The existence of a trajectory attractor is established. The work is motivated by similar studies in [12] for a energy balance model with latent heat flux and uses techniques developed in [11] and [12]. It is a continuation of [18], where an abstract global existence and boundedness result was established.

Mathematics subject classification (2010): 35K65, 35K92, 37K57, 35R10, 45D99, 58J99.

Keywords and phrases: functional reaction-diffusion equation, Volterra operator, trajectory attractor.

\section{REFERENCES}

[1] D. Arcoya, J. I. Diaz, And L. Tello, S-shaped bifurcation branch in a quasilinear multivalued model arising in climatology, J. Differential Equations, 150 (1998), 215-225.

[2] J.-P. Aubin And H. Frankows Ka, Set-valued analysis, Systems \& Control: Foundations and Analysis, 2, Birkhäuser, Boston-Basel-Berlin, 1990.

[3] R. Bermejo, J. Carpio, J. I. Díaz, And L. Tello, Mathematical and numerical analysis of a nonlinear diffusive climate energy balance model, Math. Comput. Modelling, 49 (2009), 1180-1210.

[4] V.V. Chepyzhov And M.I. VishiK, Trajectory Attractors for the 2D Navier-Stokes system and some generalizations, Topol. Methods Nonlinear Anal., 8 (1996), 217-243.

[5] V.V. CHePYZHOV AND M.I. VISHIK, Evolution equations and their trajectory attractors, J. Math. Pures Appl., 76 (1997), 913-964.

[6] V.V. Chepyzhov And M.I. Vishik, Attractors for Equations of Mathematical Physics, American Mathematical Society Colloquium Publications, 49 American Mathematical Society, Providence, RI, 2002.

[7] K. Deimling, Ordinary differential equations in Banach spaces, Lecture Notes in Mathematics, 596, Springer-Verlag, Berlin-Heidelberg-New York, 1977.

[8] K. Deimling, Multivalued differential equations, de Gruyter Series in Nonlinear Analysis and Applications, 1, Walter de Gruyter \& Co., Berlin, 1992.

[9] J.I. DíAZ, Mathematical analysis of some diffusive energy balance models in climatology, Mathematics, climate and environment (Madrid, 1991), 28-56, RMA Res. Notes Appl. Math., 27, Masson, Paris, 1993.

[10] J.I. DÍAZ, J. HeRnándeZ, And L. TELlo, On the multiplicity of equilibrium solutions to a nonlinear diffusion equation on a manifold arising in Climatology, J. Math. Anal. Appl., 216 (1997), 593-613.

[11] J.I. DÍAZ AND G. HETZER, A quasilinear functional reaction-diffusion equation arising in climatology, Equations aux dérivées partielles et applications, Articles dédiés á J.-L. Lions, Gauthier-Villars, 1998.

[12] J.I. Díaz, G. Hetzer And L. Tello, An energy balance climate model with hysteresis, Nonlinear Anal., 64 (2006), 2053-2074.

[13] J.I. DÍAZ, J. LANGA, AND J. VALERO, On the asymptotic behaviour of solutions of a stochastic energy balance climate model, Phys. D, 238 (2009), 880-887.

[14] J.I. DÍAZ, AND S. SHMAREV, Lagrangian approach to the study of level sets: application to a free boundary problem in climatology, Arch. Ration. Mech. Anal., 194 (2009), 75-103. 
[15] J.I. DíAZ, AND S. Shmarev, Lagrangian approach to the study of level sets: II. A quasilinear equation in climatology, J. Math. Anal. Appl., 352 (2009), 475-495.

[16] J.K. HALE, Asymptotic behavior of dissipative systems, Mathematical Surveys and Monographs, 25, American Mathematical Society, Providence, RI, 1988.

[17] G. HETZER, The shift-semiflow of a multi-valued evolution equation from climate modeling, Nonlinear Anal., 47 (2001), 2905-2916.

[18] G. HETZER, Global existence for a functional reaction-diffusion problem from climate modeling, to appear in AIMS Proceedings.

[19] V. Hutson, S. Martinez, K. Mischaikow, and G.T. Vickers, The evolution of dispersal, J. Math. Biol., 47 (2003), 483-517.

[20] G. Hetzer, T. Nguyen, And W. Shen, Coexistence and extinction in the Volterra-Lotka competition model with nonlocal dispersal, to appear in Commun. Pure Appl. Anal.

[21] C.-Y. KaO, Y. Lou, AND W. Shen, Random dispersal vs. nonlocal dispersal, Discrete Contin. Dyn. Syst., 26 (2010), 551-596.

[22] V. Lakshmikantham and S. Leela, Nonlinear differential equations in abstract spaces, International Series in Nonlinear Mathematics: Theory, Methods and Applications, 2, Pergamon Press, Oxford-New York, 1981.

[23] G.R. SELL, Global attractors for the three-dimensional Navier-Stokes equations, J. Dynam. Differential Equations, 8 (1996), 1-33.

[24] G.R. Sell And Y. You, Dynamics of evolutionary equations, Applied Mathematical Sciences, 143, Springer-Verlag, New York, 2002.

[25] I.I. VRabie, Compactness methods for nonlinear evolutions, Pitman Monographs and Surveys in Pure and Applied Mathematics, 32, Longman Scientific \& Technical, Harlow; John Wiley \& Sons, Inc., New York, 1987. 